WOODS, J.H., KATZ, J.L. \& WINGER, G. (1987) Abuse liabllity of benzodiazepines. Phamacology Review, 4, 251-413.

V. EAPEN, University College London Medical School, London W1N 8AA

\section{Shortage of senior registrar posts}

Sir: Recent papers in the Psychiatric Bulletin on requirements for appointment as a senior registrar (Bowen \& Cox, 1993 and Izaguirre \& Sireling, 1993) demonstrate clearly the problems facing trainees in psychiatry but only touch on the cause of the problem, i.e. the shortage of senior registrar posts. This was pointed out in our paper 'Outcome of Psychiatric Training' (Birchall \& Higgins, 1991) and since then the situation has become worse. A review of the Classified Advertisements Supplements of the British Medical Journal for four recent consecutive weeks showed advertisements for 37 posts for consultant psychiatrists and only seven posts for senior registrars in psychiatry.

Of all trainees leaving the Mersey Region Training Scheme in Psychiatry during the past eight years, 62 were successful in the membership examination. Forty-three trainees left to take up senior registrar posts, nine trainees went abroad and the remaining ten went into posts which gave them a poor chance of obtaining a senior registrar post and therefore of reaching consultant status. Of the nine trainees who went abroad, three were returning to their own country, and six were emigrating, mainly because of difficulty obtaining senior registrar posts. Of the ten trainees remaining in the United Kingdom. five were thought unsuitable for higher training because of personal qualities but the remaining five probably were suitable. So, of 62 trainees successful in passing the membership examination, $11(18 \%)$ might have become consultants in the United Kingdom were it not for the shortage of senior registrar posts.

In the Mersey region we are considering what help to give to trainees to ensure that those suitable for senior registrar training achieve this goal. It is likely that a similar situation exists in other regions. There are several vacancies for consultant posts in most health regions. Each consultant vacancy puts considerable strain on the other consultants and trainees in the unit affected, and results in impairment of training and of patient care.

The College is to be congratulated on obtaining agreement for an increase in manpower allocation of senior registrar posts for psychiatry. Unfortunately, due to financial constraints, health authorities may be reluctant to fund additional posts and it may be years before the planned increase is achieved. Urgent action is required to remove this artificial obstacle to the progress of trainees not only for their sake, but for the future of psychiatry. Unless this problem is addressed, the College's efforts may come to nought.

BIRCHALL, E. \& HigGiNs, J. (1991) The outcome of psychiatric training. Psychiatric Bulletin. 14, 357-359.

BOWEN, J. \& Cox, S. (1993) Registrars with research - the right stuff, or the wrong stuff? Psychiatric Bulletin. 17. 540-541.

IZAGUIRRE, J. \& SiRELING L. (1993) Expectations of prospective senior registrars and those who appoint them. Psychiatric Bulletin, 17, 612-614.

ERIC BIRCHALl, Fazakerley Hospital, Liverpool LO TAL

\section{Training pack for senior registrars}

Sir: Some 18 months ago I introduced a new appraisal and logbook/checklist as part of a training pack for senior registrars in the psychiatry of learning disability in Oxford. The components of the training pack are as follows.

\section{Introduction}

This brief section stresses the partnership which should exist between the trainee and supervisor. Also included is a summary of the services provided in the various placements.

\section{Logbook/checklist}

The logbook is seen as a checklist to help senior registrars build up a record of their experiences and knowledge. It is therefore intended to help direct senior registrars to those areas they may need to focus on to ensure a broad range of experiences in their training/development. It is stressed that this is not an assessment tool and should be perceived as belonging to the trainee. It also differs in many respects to the traditional logbook which is a record of cases seen or procedures carried out. It covers the following areas: assessment; formulation of problems: planning and implementation of intervention; assessment and intervention at various levels; visits to settings/agencies with people with learning disability; work with other professionals; breadth of experience; training/teaching; management development; and research.

\section{Goal sheet}

On each main clinical placement educational goals are set jointly between the educational supervisor and trainee. These are finalised with the scheme organiser at the goal planning meeting. Goals are reviewed one month into the placement, midway through the placement and at the end. The midway and final reviews involve the 
scheme organiser. Copies of the goal sheets are kept by the trainee, supervisor and scheme organiser.

\section{Evaluation sheet}

There are two evaluation forms, one for the supervisor, the other for the senior registrar. Both cover the same ground and have the following components: assessment, treatment, clinical research, training of other staff, management and organisation, and general ratings. Each section has a number of subheadings where comments can be recorded and a satisfactory/unsatisfactory rating given for each section. These can then be aggregated to give an overall satisfactory/unsatisfactory rating. These are filled in at the midway point and at the end of the placement in the presence of the scheme organiser.

The general feedback from both trainees and supervisors has been favourable so far. Feedback from them has helped modify the content and structure. I would be interested to hear other trainers'/trainees' experiences in this area which is likely to be given fresh impetus by implementation of the Calman Report. References are avallable on request.

JOHN MORGaN, Oxfordshire Learning Disability NHS Trust, Slade House, Horspath Driftway, Headington, Oxford OX3 7JH

\section{A piece of her mind}

Sir: He too was a kind man, a caring GP in an inner city practice. Now the cruel stroke of fate that robbed your psychiatrist of his very self (Psychiatric Bulletin, January 1994, 18, 12) also steals this man's mind with the relentless progression of Alzheimer's syndrome.

He too loved reading, politics, music, nature and good conversation. He too knew at the beginning what was happening and felt humiliated by the diagnosis but tried to live his life with dignity and good humour and keep his feelings to himself. To be a doctor, any doctor, with the diagnosis of Alzheimer's is indeed hard to bear.

This man though had no family apart from his three teenage children and wife who moved straight from bringing up a family to caring for a husband. She has had to give up hope of returning to work, at the mercy of inappropriate and inadequate community care in an illness where needs change constantly, to be mother and father to the children, to forego all social life, to become isolated in the task of caring and to contend with the financial implications of supporting three children through university and beyond, and the daunting prospect of caring for a husband who could live 20 years or more.

It is time for him to be the recipient of the love, care, patience and encouragement that he gave so liberally to others. But, sadly, in the real world it is not there. There is no-one else to share the burden of the disease. Yes, friends and colleagues do assume new and greater importance and their visits, now rare, are treasured. His colleagues were too busy looking after their own patients to spare much time for friendship and when, after five years, they drifted away altogether, embarrassed, bored, helpless, or who knows, afraid of what they saw, fearful that one day they too could fall victim to such devastation. what then?

It is a heartbreaking experience caring for an Alzheimer's sufferer. Rewarding moments become few and far between and that challenge once faced with determination begins to lose its way. When one wife, still in her 40 s, starts to sink under the load, too exhausted to care about how she lives each day, unable to see strength and beauty in any of those seeds and memories planted by a once-loved husband, what happens then? There is no one to pick up the pieces of her shattered life or care for her. There is no light at the end of the long tunnel that is Alzheimer's disease.

ANONYMOUS

\section{Reunion of RAF psychiatric personnel}

It is proposed to hold a reunion dinner for all current and former RAF psychiatric personnel with a view to forming a RAF Psychiatric Association. Would all eligible former members please contact F. S. Jones, Unit Manager, Psychiatric Centre, Princess Alexandra's RAF Hospital, Wroughton, Swindon SN4 OQJ, (telephone 0793812291, extension 7243). 